\title{
Gonadotroph Adenoma
}

National Cancer Institute

\section{Source}

National Cancer Institute. Gonadotroph Adenoma. NCI Thesaurus. Code C45915.

An adenoma of the anterior lobe of the pituitary gland that produces gonadotrophic hormones (FSH and/or LH) or shows evidence towards gonadotroph differentiation. The majority of cases are hormonally non-functional. Clinical manifestations include visual disturbances, hypopituitarism, headache, and acute hemorrhagic necrosis of the pituitary gland. 